\title{
Recent Temperature and Rainfall Characteristics in Dodoma Region, Central Tanzania (1961 - 2013)
}

\author{
Helena Elias Myeya
}

\begin{abstract}
This paper presents the recent temperature and rainfall characteristics in Dodoma region, central Tanzania. The study used archival temperature and rainfall data for the past 53 years (1961 - 2013). Simple linear trend analysis and Mann-Kendall test were used to establish and test for rainfall and temperature trends through Microsoft Excel (2010) and Statistical Package for Social Sciences (version 20). Results for both minimum and maximum temperature indicate a significant increased trend $(p=0.000, p=0.001)$ respectively at 0.05 significance level. Conversely, non-significant decreasing and increasing rainfall trends were noted for Bahi, Mpwapwa and Dodoma $(p=0.532, p=0.473, p=0.629)$ respectively, at 0.05 significance level. Results further indicate that rainfall variability in the study area is influenced by local, regional and global variations. From the results, it is noted that temperature and rainfall have both significant and insignificant changes. It is recommended that the observed increased temperature and declined rainfall requires more adaptation strategies than usual to reduce adverse effects as climate variability is expected to further increase in the near future.
\end{abstract}

Keywords: Climate variability, sea surface temperature, rainfall, linear regression, Tanzania

Mkwawa University College of Education, Department of Geography and Economics. Email: myeyahelena@yahoo.com

Ghana Journal of Geography Vol. 13 (1), 2021 pages 63-80

https://dx.doi.org/10.4314/gjg.v13i1.4 


\section{Introduction}

Global climate patterns have been changing mainly due to the increase of surface temperature and the spatial redistribution of precipitation (Hernandez, 2012). The world has experienced the increase in climate extremes such as droughts, floods, hurricanes, earthquakes and landslides that are all related to changes in temperature and rainfall patterns (Intergovernmental Panel for Climate Change (IPCC), 2014; World Wide Fund for Nature (WWF), 2006). Several studies such as Hernandez (2012), Salinger et al. (2005) and Ludwig et al. (2007) report that there is a constant increase in temperature in different parts of the world at varying levels. The minimum temperature is reported to increase faster than the maximum temperature (IPCC, 2014, Salinger et al., 2005).

Africa is not isolated from the global climatic changes. The continent has experienced changes in temperature and rainfall at varying levels. Changes in the extreme weather and climate events have been observed in the continent since 1950 (Alliance for a Green Revolution in Africa, (AGRA, 2014). A significant rise in temperature for Africa occurred between 1979 and 2010 (Collins, 2011) where temperature increased to about $0.5^{\circ} \mathrm{C}$ per century. However, the year 2020 is reported to be the second warmest year ever experienced (McGrath, 2020). Studies by Abaje and Oladipo (2019), Adu-Boahen et al. (2019) and Sarr, (2012) reports increased temperature trends in West Africa regions. In Tanzania, temperature has also been reported to increase at varying rates in different parts of the country (United Republic of Tanzania, 2011; Swai et al., 2012) which is reported to be influenced by El Nino Southern Oscillation (ENSO) (Mafuru \& Guirong, 2020; Park et al., 2020).

Apart from temperature conditions, the global precipitation has also been reported to either increase or decrease depending on geographical location (Hernandez, 2012). The African continent has experienced rainfall variability since 1960s (Umar \& Bako, 2019; Owusu, 2009; Sivakumar et al., 2005). Both increased and decreased rainfall trends have been reported in some areas of the continent. Indeed, the declining annual rainfall was reported in Ghana since the early 1970s (Owusu, 2009), while Abaje et al. (2018) reported the increased rainfall trends in parts of Nigeria. Similarly, increased rainfall trend was reported in Ethiopia and East Africa highlands (Collier et al., 2008; IPCC, 2007) as opposed to the declined rainfall trends reported in dry lands of Northern and Southern Africa (Collier et al., 2008). Tanzania, like other East African countries has experienced both increased and declined rainfall trends reported in different parts of the country (Lyamurenye et al., 2019; Mongi et al., 2010; Lyimo and Kangalawe, 2010). 
Several studies such as Yang et al. (2015), Collier et al. (2008), Curtis (2008), Leroux, (2001) and Nicholson (2001) have highlighted that the variability in rainfall in this region is largely influenced by large-scale climate modes including the El Nino Southern Oscillation (ENSO), the Indian Ocean Dipole (IOD) and the movement of inter-tropical convergence zone (ITCZ). ENSO has indicated multiple effects in precipitation where warm ocean currents have influenced higher rainfall while cold ocean currents have influenced lower rainfall (Mafuru \& Guirong, 2020; Park et al., 2020).

Although changes in climate variables like temperature and rainfall have been noted throughout Tanzania, little is known about recent temperature and rainfall characteristics in the Dodoma region. The present research is intended to provide a comprehensive analysis on temperature and rainfall characteristics in Dodoma region for the past 53 years (1961 -2013) and explain the influencing factors on the climate variable trends. The finding from the present research is a contribution to the existing body of knowledge on the analysis of temperature and rainfall characteristics at local levels. It might also be useful for policy formulation on appropriate ways of adaptation to the changing climate. Additionally, the results on temperature and rainfall analysis in the study area would also be helpful in future climate projections.

\section{Materials and Methods}

\section{The study area}

Dodoma region (Figure 1) lies in the central Tanzania mainland between latitudes $4^{\circ}$ to $7^{\circ}$ South and longitude $35^{\circ}$ to $37^{\circ}$ East (URT, 2011). The region occupies about $41,310 \mathrm{~km}^{2}$ of which $85 \%$ is a potential agricultural land. The Dodoma region is largely a plateau rising gradually from some 830 metres above the sea level in Bahi swamps to 2000 metres above the sea level (m.a.s.l) in the highlands, north of Kondoa (URT, 2011). The region has seven (7) districts namely: Bahi, Chamwino, Chemba, Dodoma Municipality, Kondoa, Kongwa and Mpwapwa. However, the analysis of the current study is based in Bahi, Dodoma and Mpwapwa.

\section{Climatic characteristics}

Temperature and rainfall distribution in the Dodoma region vary depending on the location. The area receives rainfall in December through May for 70 to 90 days of rain per year (500 to $800 \mathrm{~mm}$ although some parts receive below $500 \mathrm{~mm}$ ) (URT, 2011). Rainfall in the Dodoma 
region is unevenly distributed and a large part of the region receives a relatively low and unpredictable rainfall in frequency, amount and distribution. About $85 \%$ of the rainfall in the region falls in four months between December and March and the annual mean rainfall is 580 mm (URT, 2011; URT, 2007). Generally, rainfall tends to be unreliable and all areas are drought prone. Meanwhile, temperature in Dodoma region varies according to location, relief and altitude. Some areas experience higher temperatures than others do. The study area features a semi-arid climate with warm to hot temperatures throughout the year. The area receives mean annual temperature ranging between $17^{\circ} \mathrm{C}$ and $29^{\circ} \mathrm{C}$ (URT, 2011).

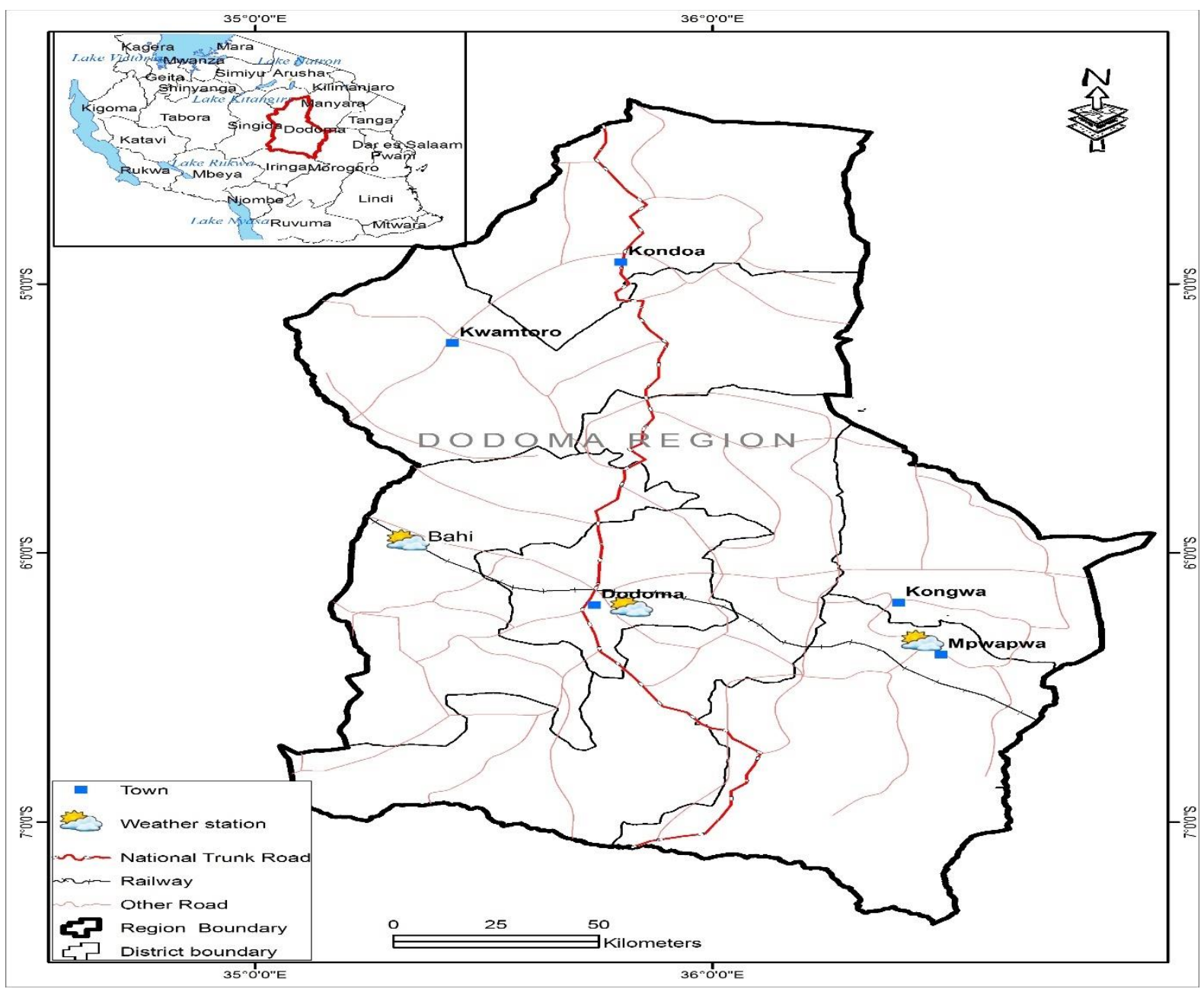

Figure 1: Study meteorological stations in the study area

\section{Data collection techniques}

Site visits to the meteorological offices in Dodoma and Dar es Salaam regions were made to collect monthly temperature and rainfall data. Additionally, some temperature and rainfall data for the study area were also obtained from the website of the World Meteorological Organisation (WMO) (2014) to supplement the collected data from the meteorological stations. 
To ensure representation of a wider area, rainfall data from three different stations located in three districts (Bahi, Dodoma urban, and Mpwapwa) (Figure 1 and Table 1) were recorded. However, Temperature data were gathered from one station (Dodoma) because other stations had no such information as of the time of the study. The data collected for both rainfall and temperature were recorded on monthly basis for which temperature was in terms of degree centigrade and rainfall was in millimetre scales.

Table 1: Location of the three weather stations

\begin{tabular}{lrrrl}
\hline Stations & Latitude $\left(^{\circ}\right)$ & Longitude $\left(^{\circ}\right)$ & Elevation $(\mathrm{m})$ & Years \\
\hline Bahi & 5.9734 & 35.3231 & 839 & $1961-2013(53)$ \\
\hline Dodoma & 6.1023 & 35.4431 & 1120 & $1961-2013(53)$ \\
\hline Mpwapwa & 6.2054 & 36.2912 & 948 & $1961-2013(53)$ \\
\hline
\end{tabular}

\section{Data analysis techniques}

Temperature and rainfall data were time series thus, prompted to test for unit root problem and linearity before analysis was conducted. Augmented Dickey - Fuller (ADF) test was undertaken to test for unit root problem (Blanc, 2012; Amikuzino and Donkoh, 2012). The ADF test showed that there was no unit root problem associated with the data thus, enabled the analysis to proceed to the next stage.

Simple linear trend analysis and Mann-Kendall test were applied to establish and test for temperature and rainfall trends. Mann-Kendall test (Kendall's tau) is a non-parametric measurement that is used to test the randomness against the trend (Caloiero et al., 2009). The test was intended to show how strong the trend of the variable was increasing or decreasing (Karmeshu, 2012). By using Kendall's test, p-values of less than or equals to the significance level (0.05), indicate the existence of significant trend while the p-value larger than the significance level (0.05) indicate insignificant trend. Moreover, the Statistical Package for Social Sciences (SPSS version 20) was used to compute the Mann-Kendall test where positive values indicated increasing trends while negative values indicated declining trend. Significant or insignificant trend was determined using p-values.

Furthermore, linear trend lines were plotted for temperature and rainfall using Microsoft excel 2010. Simple linear trend analysis was chosen because it was found relevant and appropriate for identifying the unknown trends. Thus, simple linear trend helped to establish graphs that indicate coefficient estimates for temperature and rainfall. Simple linear trend analysis 
indicated whether the change was positive or negative. In this case, simple linear line has an equation as follows:

$$
y=m x+b
$$

Where: $y$ is the dependent variable;

$m$ is the slope of the line; $x$ is the independent variable and $b$ is the intercept.

\section{Results and Discussion}

\section{Mean annual maximum and minimum temperature}

The results on temperature analysis over the past 53 years (i.e., 1961 to 2013) presented in Figures 2 and 3, indicate increased values for both the mean annual minimum and maximum temperature. The fitted linear trends in the minimum temperature (Tmin) and maximum temperature $(\operatorname{Tmax})$ are statistically significant at the 0.05 level of significance $(\mathrm{p}=0.000, \mathrm{p}=$ 0.001 ) respectively. The minimum temperature increased rapidly (slope $0.019^{\circ} \mathrm{C}^{-1}$ ) than the maximum $\left(0.011^{\circ} \mathrm{C}^{-1}\right)$. This was explained by a higher percentage $(39.7 \%)$ of the observed variance in the minimum $\left(\mathrm{R}^{2}=0.397\right)$ than that observed of $(16.6 \%)$ in the maximum $\left(\mathrm{R}^{2}=\right.$ 0.166). Based on these results, it is noted that over the past 53 years $(1961-2013)$, the minimum temperature in the Dodoma region has increased rapidly than the maximum temperature. This has an implication on the increase of hot days as compared to cold ones.

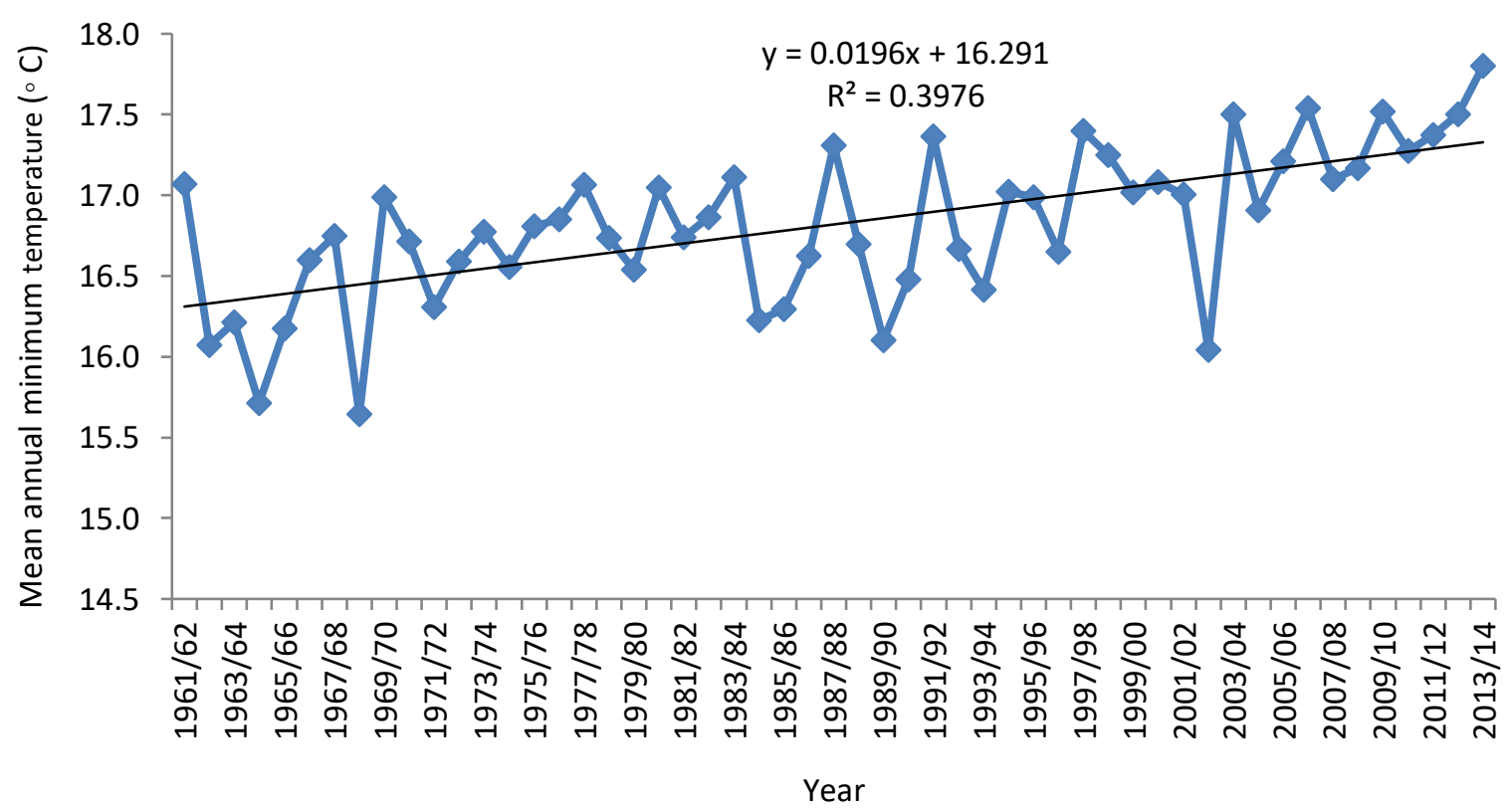

Figure 2: Mean annual minimum temperature in Dodoma, 1961 to 2013

Source: Computation based on TMA and WMO Data 


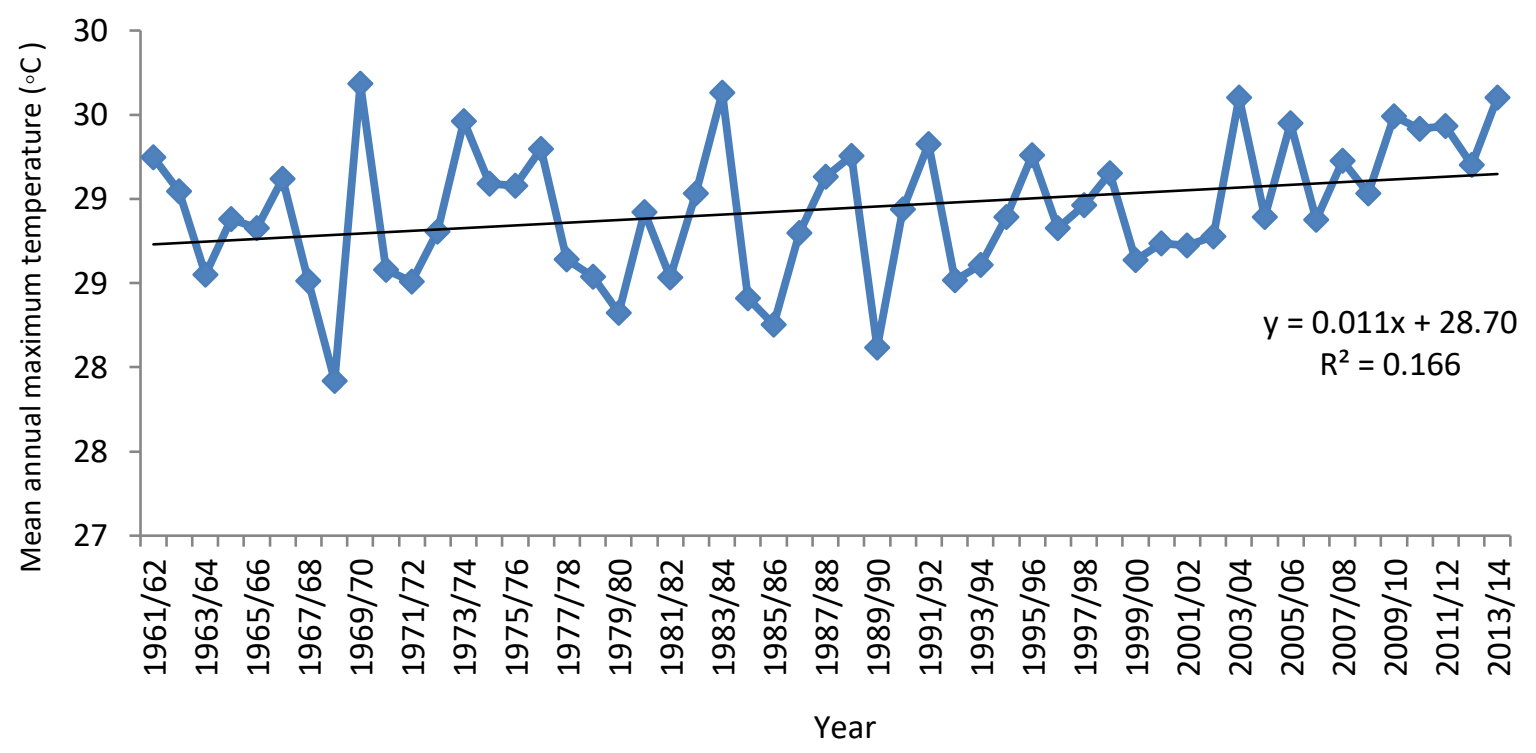

Figure 3: Mean annual maximum temperature in Dodoma, 1961 through 2013

Source: Computation based on TMA and WMO Data

\section{Mean monthly temperature}

The research results in Figure 4 indicate the mean monthly temperature in Dodoma region having higher values in October, November and December as compared to other months while mean minimum monthly temperature has shown significant increased trends in all months except May, June and October. Moreover, the mean monthly maximum temperature has depicted slightly different rates with insignificant decreasing values in March and October and insignificant increasing rates in the other months except May.

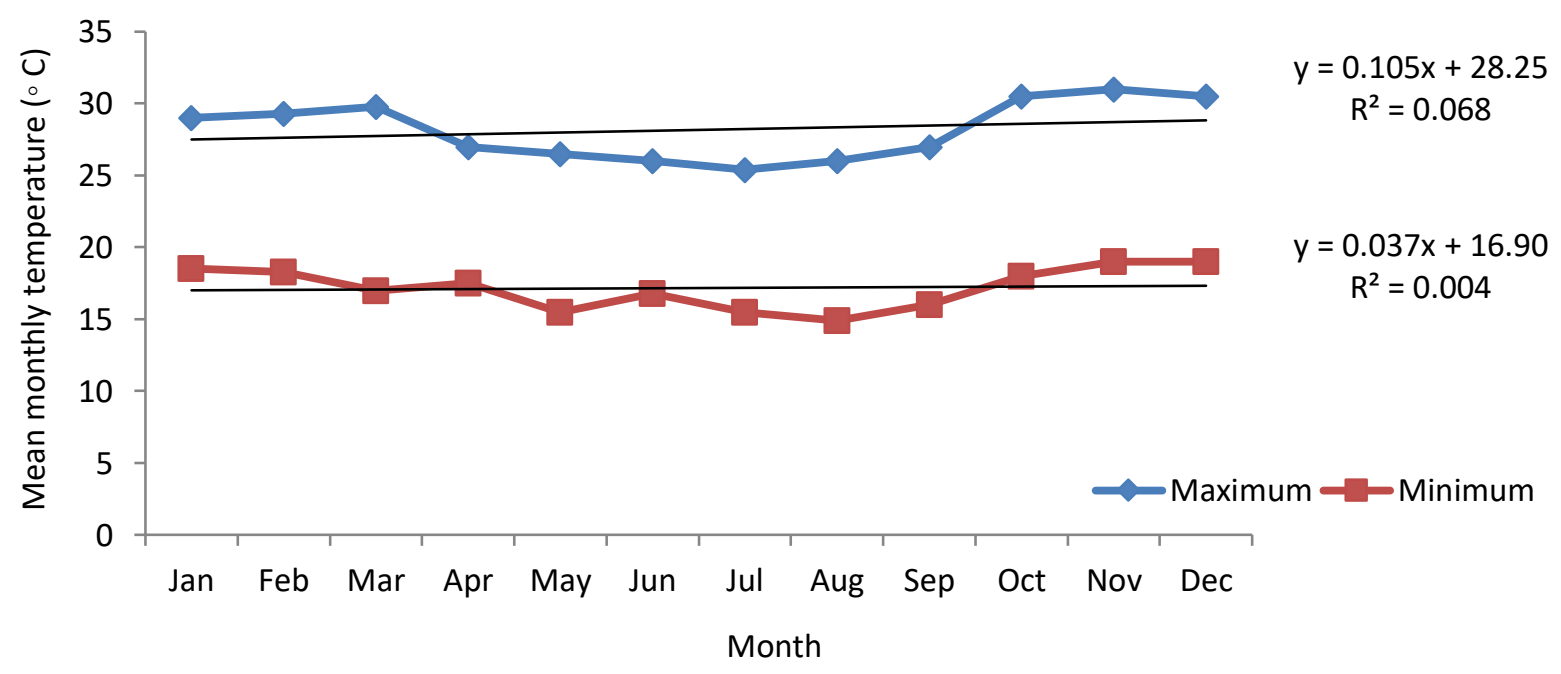

Figure 4: Mean monthly temperature in Dodoma, 1961 to 2013

Source: Computation based on TMA and WMO Data 


\section{Diurnal temperature range}

Diurnal Temperature Range (DTR) of the study area for the past 53 years $(1961-2013)$ shown in Figure 5 indicates decreasing trend. The decline of DTR with a slope of $0.0091^{\circ} \mathrm{C} \mathrm{y}^{-1}$ implies a decrease by $8.8 \%$ of variance from 1961 to 2013. A negative value implies a lower increase in the maximum temperature as compared to the minimum temperature. This is associated with the increase of hot days and nights as compared to cold days and nights. These results are in line with what is reported by Easterling et al. (1997) who report that increased temperature values in both maximum and minimum temperature influence the variation in the Diurnal Temperature Range (DTR) as it has been observed in the current research results.

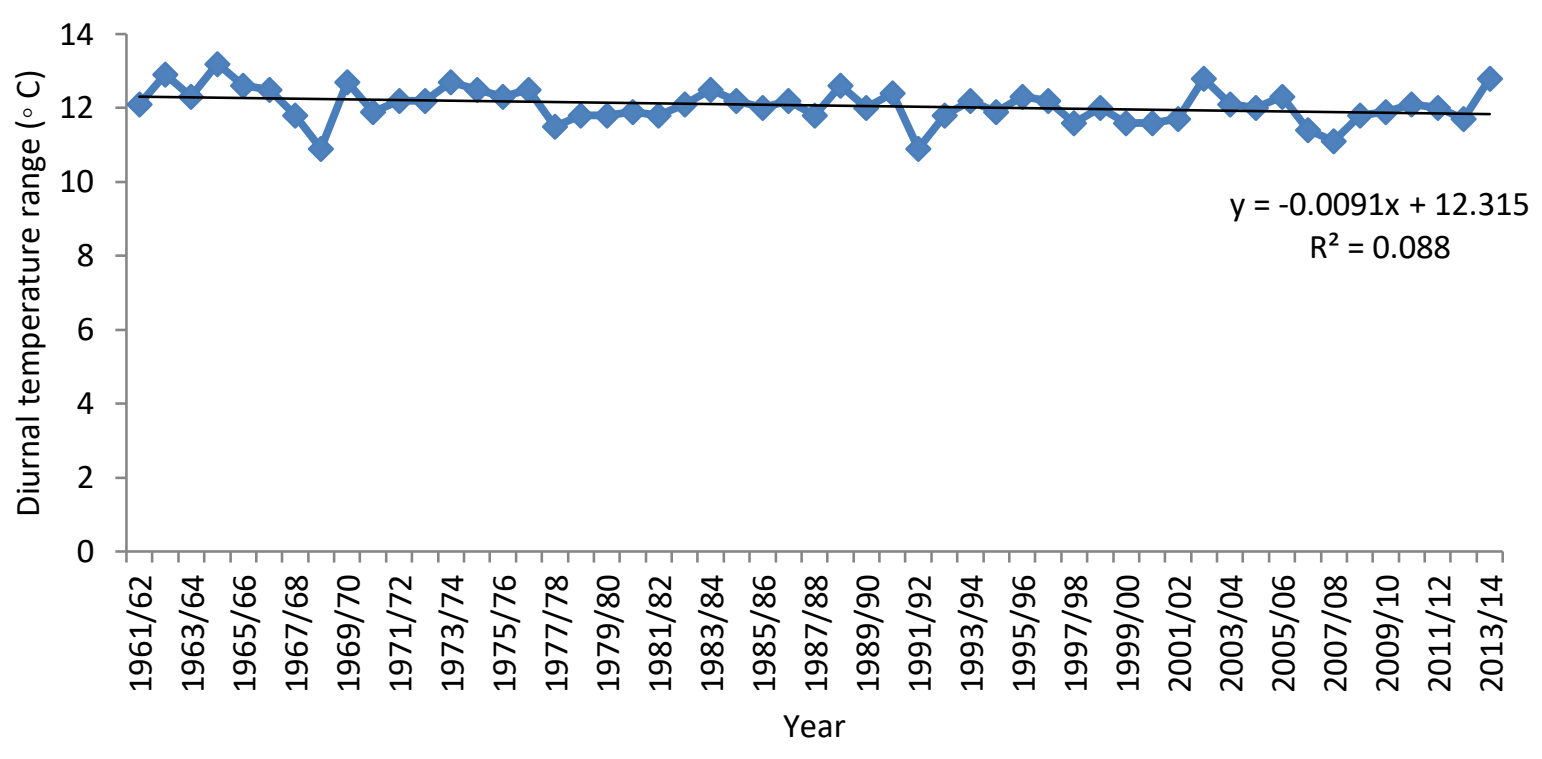

Figure 5: Diurnal temperature range, 1961 to 2013

Source: Computation based on TMA and WMO Data

Based on the results of the current research, temperature in the study area has slightly changed for the past 53 years (1961 to 2013). The average maximum temperature has changed from $29^{\circ} \mathrm{C}$ to $29.7^{\circ} \mathrm{C}$ in 1961 and 2013 respectively with an increase of $0.7^{\circ} \mathrm{C}$ for the past 53 years, while the average minimum temperature has changed from $17^{\circ} \mathrm{C}$ to $18.4^{\circ} \mathrm{C}$ with an increase of $1.4^{\circ} \mathrm{C}$ for the study period. The overall average of both the maximum and minimum temperature has also changed from $23^{\circ} \mathrm{C}$ to $24^{\circ} \mathrm{C}$ (1961 to 2013) implying an increase of $1^{\circ} \mathrm{C}$ for the study period. These results concur with those by 1PCC (2014), which reports on the increase of the global temperature that has also resulted to the increase in temperature at local levels and the semiarid areas of Dodoma region in particular. The results are also in line with what is reported by Latha et al. (2012) and Sivakumar et al. (2005) in India, Malik et al. (2012) in Pakistan, Aondoakaa (2012) in Nigeria, Sarr (2012) in dry land areas of West Africa, Bryan 
et al. (2009) in Ethiopia and South Africa, Owusu-Sekyere et al. (2011) and Owusu (2009) in Ghana, Kangalawe and Lyimo (2013), Lyimo and Kangalawe (2010) as well as Mary and Majule (2009) in Tanzania who also reported on increased trends in temperature.

\section{Mean annual rainfall}

The results on rainfall analysis in Figure 6 indicate insignificant decreasing trends $(p=0.532$, $\mathrm{p}=0.473$ ) at 0.05 significance level for Bahi and Mpwapwa stations respectively. The decline of rainfall for Bahi station with a slope of $1.519 \mathrm{~mm} \mathrm{y}^{-1}$ implies a decrease by $3.7 \%$ of variance from 1961 to 2013, while the decline of rainfall for Mpwapwa station, which has a slope of $1.673 \mathrm{~mm} \mathrm{y}^{-1}$ implies a decrease by $2.5 \%$ of variance for the study period. Although a decrease in rainfall was recorded in these two stations, more decrease was recorded for Bahi when compared with that of Mpwapwa station. However, for both stations, the decrease was statistically insignificant.

While rainfall has indicated decreasing trends for Bahi and Mpwapwa stations rainfall analysis for the Dodoma station indicated statistically insignificant increasing trends, which is $(\mathrm{p}=0.629)$ at 0.05 significance level. The increase in rainfall for the Dodoma station with a slope of $0.476 \mathrm{~mm} \mathrm{y}^{-1}$ implies the increase by $0.3 \%$ of variance over the past 53 years. A comparison of rainfall patterns in each station indicates that at the beginning of the study period (1961), rainfall was high for Mpwapwa compared to that of Bahi and Dodoma stations. It was also revealed that all stations had higher rainfall values in some years specifically in 1967/68, 1968/69, 1989/90, 1997/98 and 2007/08. 


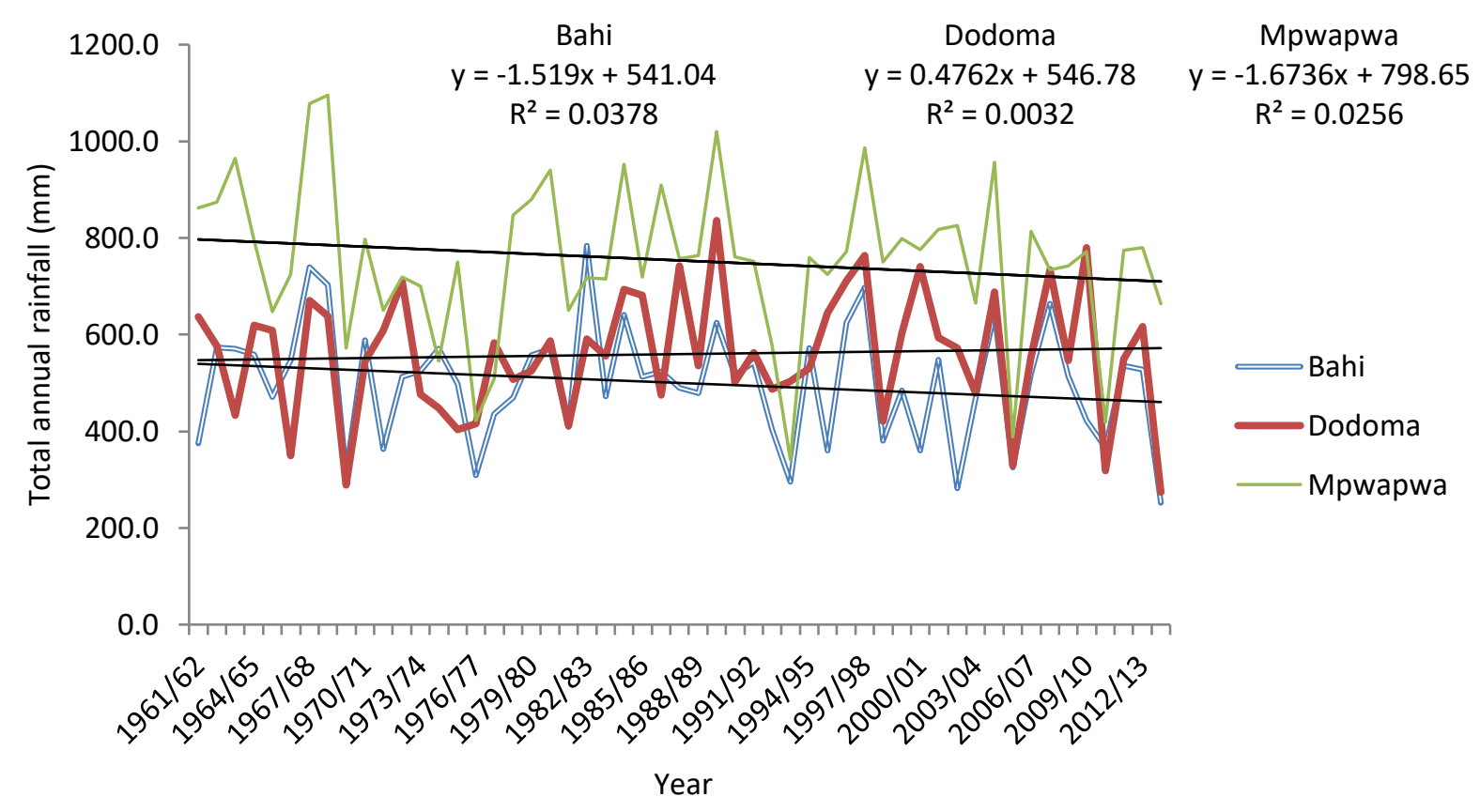

Figure 6: Mean annual rainfall for Bahi, Dodoma and Mpwapwa stations, 1961 to 2013 Source: Computation based on TMA and WMO Data

Apart from increased trends in rainfall patterns for some years, rainfall patterns has also shown declining trends for some years. Higher declining trends in rainfall for all three stations were recorded in 1969/70, 1976/77, 1992/93, 1993/94 and 2005/06 which are linked with the global events of warm and cold episodes.

\section{Decadal rainfall analysis}

The decadal rainfall analysis shown in Figure 7 and 8 indicates that in the first decade (1961 1970) rainfall for Bahi and Mpwapwa stations were above the mean, while Dodoma station received lower rainfall. Ten years later (second decade), rainfall dropped in all stations and Mpwapwa recorded the highest fall. Conversely, in the third decade (1981-1990), all the three stations recorded higher rainfall amount than the mean as opposed to the fourth decade (1991 -2000) where rainfall dropped in Bahi and Mpwapwa. The last decade (2001 - 2010) indicates rainfall to be lower than the mean for all the three stations, Mpwapwa being the most vulnerable station. 


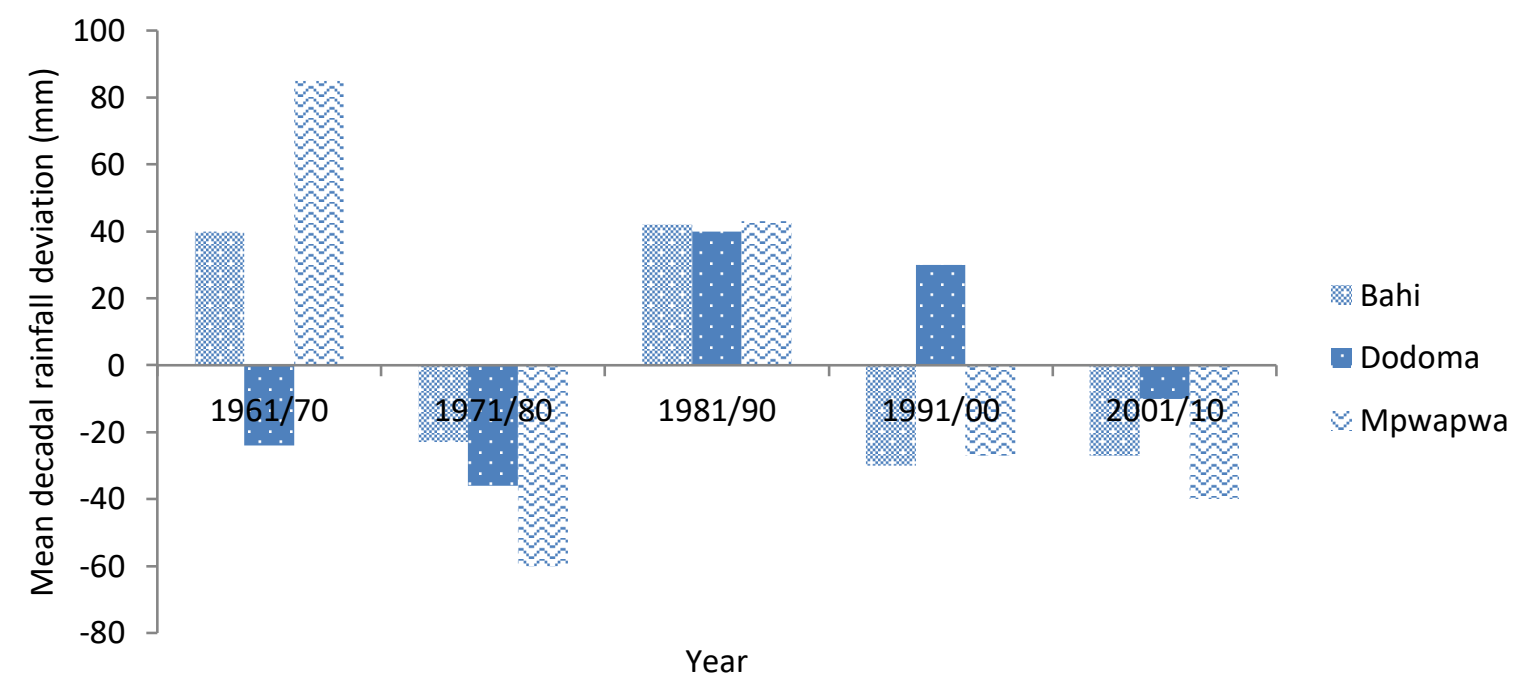

Figure 7: Mean decadal rainfall for Bahi, Dodoma and Mpwapwa stations, 1961 to 2010 Source: Computation based on TMA and WMO Data

As it was observed in mean annual rainfall (Figure 6), the fitted linear equation (Figure 8) also showed decreasing trends for Mpwapwa and Bahi stations, while the Dodoma station demonstrated increased rainfall trends under decadal analysis. However, the increase and decrease to all stations were not statistically significant.

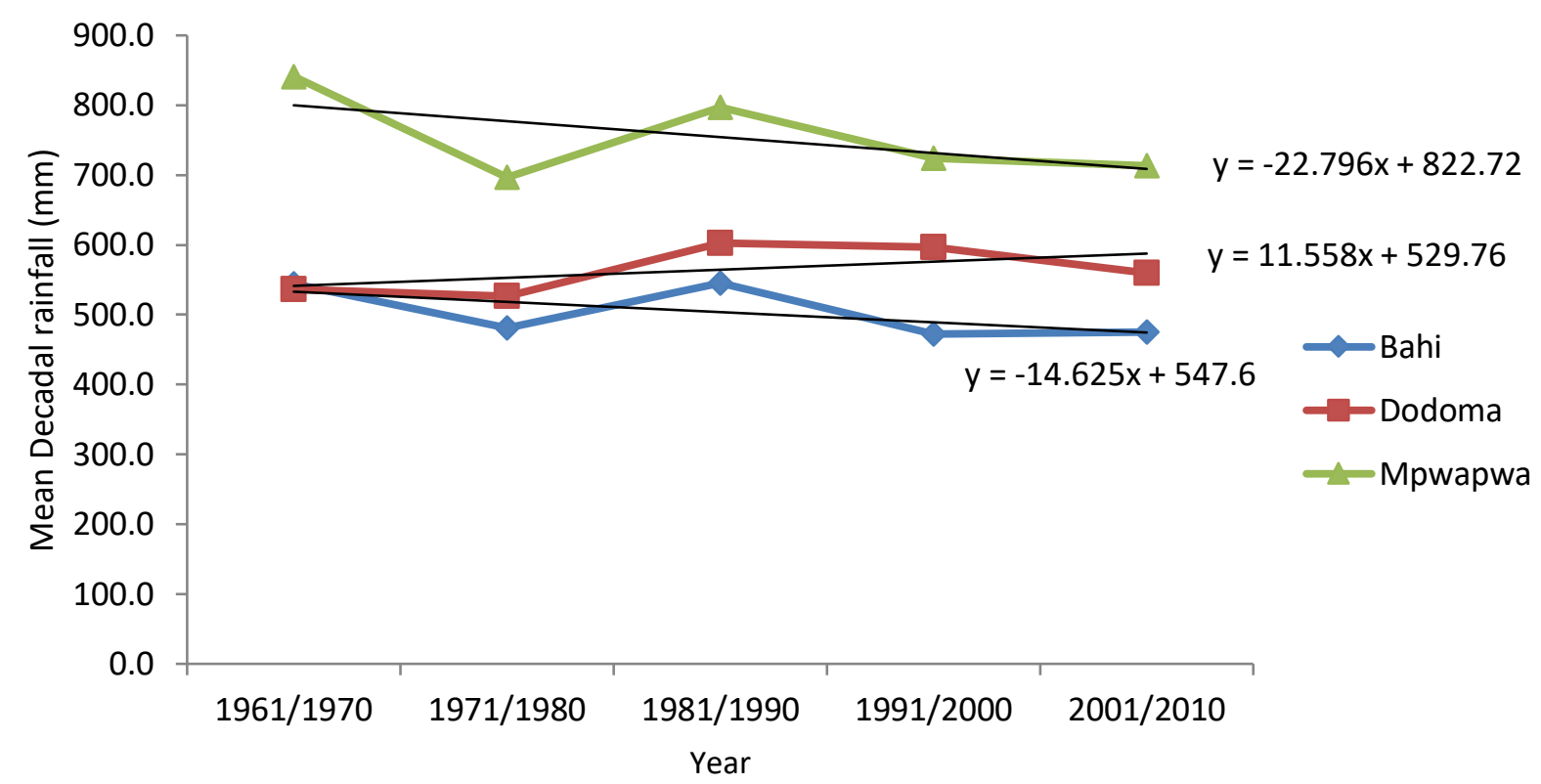

Figure 8: Mean decadal rainfall for Bahi, Dodoma and Mpwapwa stations, 1961 to 2010 Source: Computation based on TMA and WMO Data

As it has been reported in the literature, the climate of Africa, Tanzania in particular is largely influenced by the El Nino Southern Oscillation (ENSO) and Sea Surface Temperature (SSTs) of the Indian and Atlantic oceans which influences the inter-annual and inter-decadal 
variability (Nicholson, 2001). Therefore, the observed decadal variability in the study area is explained based on the influence of ENSO and SST.

Further rainfall analysis for Dodoma region was carried out (Table 2) to determine rainfall descriptive statistics for all stations. The descriptive statistics for Bahi indicated the highest rainfall $(783.8 \mathrm{~mm})$ recorded in $1982 / 83$, while $252.1 \mathrm{~mm}$ was the lowest rainfall amount recorded in 2013/14. The mean rainfall for the Bahi station for the period understudy was $504.5 \mathrm{~mm}$, while the observed standard deviation was $120.1 \mathrm{~mm}$. Moreover, results for the Dodoma station indicates $836 \mathrm{~mm}$ as the highest amount recorded in 1989/90 and the lowest amount (274mm) was recorded in 2013/2014. The mean rainfall for this station was $559.6 \mathrm{~mm}$ with a standard deviation of $129.4 \mathrm{~mm}$. Furthermore, descriptive statistics for Mpwapwa station indicated the highest rainfall amount of $1095 \mathrm{~mm}$ recorded in $1968 / 69$, while $341 \mathrm{~mm}$ was the lowest rainfall amount recorded in 1993/94. The mean rainfall in Mpwapwa station was $753.5 \mathrm{~mm}$ with the, observed standard deviation of $161.4 \mathrm{~mm}$.

Table 2: Descriptive statistics on rainfall for three weather stations

\begin{tabular}{llrrr}
\hline $\begin{array}{l}\text { Weather } \\
\text { stations }\end{array}$ & Highest & Lowest & $\begin{array}{c}\text { Mean Annual rainfall } \\
(\mathrm{mm})\end{array}$ & Standard deviation Rainfall (mm) \\
\hline Bahi & 783.8 & 252.1 & 504.5 & 120.1 \\
\hline Dodoma & 836.3 & 274.2 & 559.6 & 129.4 \\
\hline Mpwapwa & 1095.2 & 341.1 & 753.5 & 161.4 \\
\hline
\end{tabular}

From these statistics, it is noted that Mpwapwa station recorded the higher values in rainfall for both maximum and minimum as compared to Bahi and Dodoma stations. Among the three stations, Bahi indicated lower values for both the maximum and minimum records. This implies that Bahi district is more vulnerable to rainfall variations than the other two studied districts of the Dodoma region.

\section{Mean monthly rainfall}

The results for the three weather stations shown in Figure 9 indicate declining trends in mean monthly rainfall for all weather stations understudy. Variations on the intensity and amount of rainfall were observed between one station and the other. The mean monthly rainfall for Bahi station showed declining trends in January, April, May and December, while in Dodoma station, declining trends was observed in January, April, May and November. Furthermore, the 
mean monthly rainfall for Mpwapwa station indicates declining trends in January, May and November.

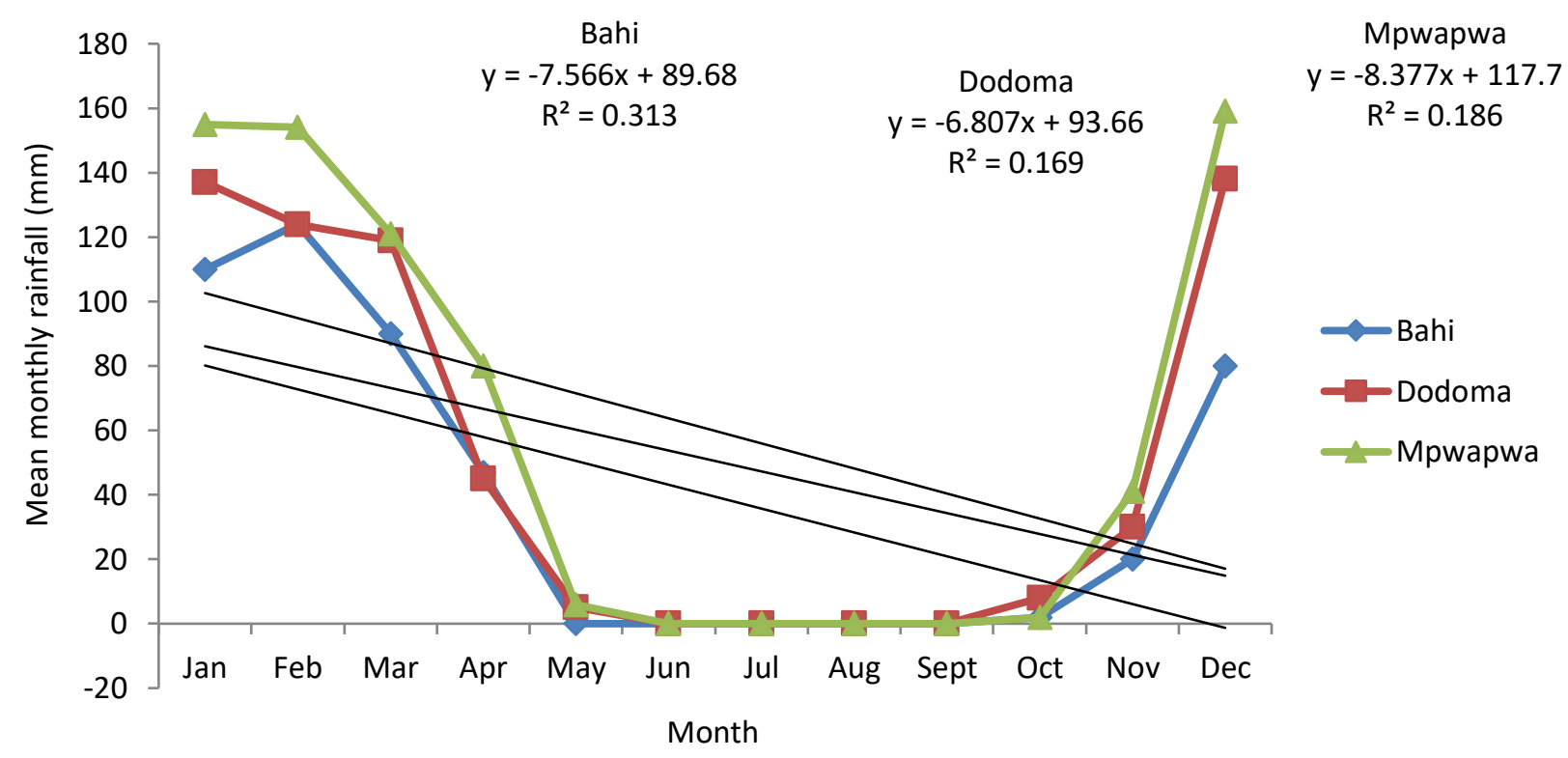

Figure 9: Mean monthly rainfall for three stations, 1961 to 2013

Source: Computation based on TMA and WMO Data

There have been similar results by other researchers in Tanzania on rainfall decline in other semiarid areas of Tanzania based on meteorological data notably Lyimo and Kangalawe (2010) in Shinyanga region from 1973 to 2008 and Mary and Majule (2009) in Singida region from 1984 to 2004 who also reported on declining rainfall trends in the studied areas.

\section{Rainfall determinants}

The rainfall in Tanzania is highly influenced by the Pacific and Indian Ocean currents. Warm air holds more moisture than cool air and this brings in more moisture from the Pacific and Indian Ocean to East Africa (Manatsa et al., 2011). This trend affects rainfall patterns in the East African countries, Tanzania in particular. Warmer temperature causes higher rainfall, while cooler temperature causes low rainfall (Park et al. 2020, McGrath, 2020, Mafuru and Guirong, 2020 \& Recha et al. 2013). Additionally, a study by Yang et al. (2015) reports that the bimodal and unimodal rainfall cycles observed in East Africa (Tanzania in particular) is a result of the annual cycle of monsoonal winds that combines with the annual cycle of Sea Surface Temperature (SSTs).

The research results in Figure 6 show rainfall variability in three weather stations of Bahi, Dodoma and Mpwapwa with varying rates. The results indicate that, for the past 53 years 
Mpwapwa station recorded higher amount of rainfall for the study period as compared to Dodoma and Bahi stations. Though rainfall trends in the study area has indicated some variations due to topographical differences, rainfall patterns in this area have both local and external influence. Literature (Agrawala et al., 2003) indicates that Tanzania's precipitation is governed by two rainfall regimes, namely: bimodal and unimodal regimes. Bimodal rainfall, comprise long rains (Masika) between March - May and short rains (Vuli) between October and December which, mostly falls in northeastern, northwestern and the northern parts of the coastal belt. A unimodal rainfall pattern, with most of the rainfall falling between December April is more typical in southern, central, western, and southeastern parts of the country (Agrawala et al., 2003).

Dodoma region is located in the central part of the country and is characterised by unimodal rainfall regime. According to the URT (2007), rainfall in Dodoma region varies with altitude. Large part of the region receive lower rainfall amount with exception of few areas which receive moderate amount of annual rainfall. These areas include the mountainous parts of East and South Mpwapwa, Kongwa forests, parts of Kondoa and Chenene hills as well as parts of south west of Dodoma town.

As explained earlier, rainfall in Dodoma region is influenced by local, regional and global characteristics. The global influence on rainfall characteristics in the study area is linked with the global occurrence of warm and cold El Nino Southern Oscillation (ENSO episodes) reported by Curtis (2008). Based on the observed variations, one can plausibly propose that rainfall patterns in the Dodoma region is associated with both warm and cold ENSO events that are determined by SSTs. The recent reported rainfall patterns are highly associated with episodes of high and low rainfall (warm and cold ENSO) events recorded globally. A good example of warm ENSO episodes in the study area was high rainfall of above the mean (580 $\mathrm{mm}$ ) recorded in 1967, 1982, 1989, 1997, 2004 and 2007 in the three stations. Conversely, cold ENSO effects of lower rainfall were observed in 1964, 1969, 1974, 1976, 1984, 1992, 2005, 2010 and 2013 of which rainfall records in three stations were below the mean annual rainfall $(580 \mathrm{~mm})$. From these records, it is noted that variations in rainfall intensity for the three stations concur with the global events of warm and cold episodes. These results are in line with the research findings by Recha et al. (2013), Marchant et al. (2007) and King'uyu et al. (1999) who also observed the influence of ENSO events on East Africa rainfall patterns. 


\section{Conclusion and Recommendations}

The research investigated the temperature and rainfall characteristics in the Dodoma region based on meteorological data. Temperature trend analysis has shown significant increased trends for both maximum and minimum temperature. Findings on rainfall analysis have indicated insignificant decreasing trends for Bahi and Mpwapwa, while Dodoma station indicate insignificant increasing trend. The reported variations in temperature and rainfall in Dodoma region have been noted to be influenced by the local, regional and global variations. From the results, it is noted that temperature and rainfall have both significant and insignificant changes. It is recommended that the observed increased temperature and declined rainfall requires more adaptation strategies than usual to reduce adverse effects as climate variability is expected to further increase in the near future.

\section{Limitation of the study}

Analysis of temperature and rainfall for this particular research based on archival data collected from different sources. It should also be agreed that it is difficult to find a well-detailed historic climate data as there appears to be some percentage of data that can miss for various reasons. For this particular study, the intention was to cover more than 53 years, but long-term rainfall and temperature data were missing to the study stations, therefore analysis based on the available data. For that reason, results of the present research may have been affected in one way or another though various mitigation measures were taken to reduce the possibilities that would affect the results. Additionally, the current rainfall and temperature analysis has based on three and one weather station respectively, of which may limit generalisation of the research findings in a wider context.

\section{Acknowledgements}

The author extends her sincere thanks to the Tanzanian Meteorological Agency (TMA) and the World Meteorological Organisation (WMO) website for supplying temperature and rainfall data used in this study. 


\section{References}

Abaje, I. B., \& Oladipo, E. O. (2019). Recent Changes in the Temperature and Rainfall Conditions Over Kaduna State, Nigeria. Ghana Journal of Geography, 11 (2), 127-157. Abaje, I. B., Achiebo, P. J., \& Matazu, M. B. (2018). Spatio-Temporal Analysis of Rainfall Distribution in Kaduna State, Nigeria. Ghana Journal of Geography, 10 (1), 1-21.

Adu-Boahen, K., Dadson, I. Y., \& Halidu, M. A. (2019). Climatic Variability and Food Crop Production in the Bawku West District of the Upper East Region of Ghana. Ghana Journal of Geography, 11 (1), 103-123.

Alliance for a Green Revolution in Africa (AGRA) (2014). Africa agricultural status report: Climate change and smallholder agriculture in sub Saharan Africa, Nairobi, Kenya.

Amikuzino, J., \& Donkoh, S. A. (2012). Climate variability and yields of major staple food crops in Northern Ghana. African Crop Science Journal, 20 (2), 349-360.

Aondoakaa, S. C. (2012). Effects of climate change on agricultural productivity in the Federal Capital Territory (FCT), Abuja, Nigeria. Ethiopian Journal of Environmental Studies and Management, 5 (4), 559-566.

Agrawala S., Moehner A, Hemp A. van Aalst M, Hitz S, Smith J, Meena, H, Mwakifwamba, SM, Hyera, T, Mwaipopo, O. U. (2003). Development and climate change in Tanzania: focus on Mount Kilimanjaro. http://www.oecd.org/env/cc/21058838 retrieved on 14th February 2017.

Blanc, E (2012). The impact of climate change on crop yields in Sub-Saharan Africa. American Journal of climate change, 1, 1 - 13, http://dx.doi.org/10.4236/ascc.2012.11001 accessed on 15th November 2018.

Bryan, E., Deressa, T. T., Gbetibouo, G. A., \& Ringler, C. (2009). Adaptation to climate change in Ethiopia and South Africa: options and constraints. Environmental Science \& Policy, 12 (4), 413- 426.

Caloiero, Tommaso., \& Roberto (2009). Trend detection of annual and seasonal rainfall in Calabria (Southern Italy). International Journal of Climatology, 31, 44-56.

Collier, P., Conway, G., \& Venables, T. (2008). Climate change and Africa. Oxford Review of Economic Policy, 24 (2), 337-353.

Collins, J. M. (2011). Temperature variability over Africa. Journal of climate, 24 (14), 36493666.

Curtis, S. (2008). The El Nino-Southern oscillation and global precipitation. Geography Compass, 2/3, 600-619.

Easterling, D. R., Horton, B., Jones, P. D., Peterson, T. C., Karl, T. R., Parker, D. E., \& Folland, C. K. (1997). Maximum and minimum temperature trends for the globe. Journal of Science, 277 (5324), 364-367.

Hernandez, J.J. (2012). Spatial and temporal changes in precipitation in Pueto Rico from 1956 - 2010. Unpublished MA thesis; the graduate faculty of the University of Akron.

Intergovernmental Panel for Climate Change (IPCC), (2007). Climate change impacts, adaptations and vulnerability: Contribution of working group II to the fourth assessment report of IPCC, Cambridge University Press, Cambridge United Kingdom. 
Intergovernmental Panel for Climate Change, IPCC (2014). Climate change: Impacts, Adaptation and Vulnerability: Summary for policy makers. Cambridge University Press, Cambridge United Kingdom.

Kangalawe, R. M., \& Lyimo, J. G. (2013). Climate change, adaptive strategies and rural livelihoods in semiarid Tanzania. Natural Resources, 4 (3), 266-278, http://search.proquest.com/docview/1425433368?accountid=10920. retrieved on $20^{\text {th }}$ November 2019.

Karmeshu, N. (2012). Trend detection in annual temperature \& precipitation using the Mann Kendall Test. A case study to assess climate change on selected States in the Northeastern United States, USA.

King'uyu, S., Ogallo, L., \& Anyamba, E. (1999). Recent trends of minimum and maximum surface temperatures over Eastern Africa. Journal of Climate, 13, 2876 - 2886.

Latha, A., Gopinath, M \& Bhat, A. (2012). Impact of climate change on rain fed Agriculture in India; A case study of Dharwad. International Journal of Environmental Science and Development, 3 (4), 368 - 371.

Leroux, M. (2001). The meteorology and climate of tropical Africa. Praxis Publishing: Chichester.

Ludwig,F., Terwisscha, C.S., Verhagen,J., Kruit,B., Lerland, E., Dellink,R., Bruin, K., \& Kabat, P. (2007). Climate change impacts on developing countries - EU accountability; Policy department economics and scientific policy.

Lyamurenye E, Wanyonyi S.W and Mbete D.A, (2019). Analysis and modelling of extreme rainfall: Acase study for Dodoma, Tanzania, Asian Journal of Probability and Statistics, 3 (2). 1 - 29.

Lyimo, J.G \& Kangalawe, Y,M. (2010). Vulnerability and adaptability strategies to the impacts of climate change and variability, the case of rural households in semi - arid Tanzania, The Journal of Environmental Economics, 1, 2.

Mafuru, K. B., \& Guirong, T. (2020). The influence of ENSO on the upper warm temperature anomaly formation associated with the March-May heavy rainfall events in Tanzania. International Journal of Climatology, 40(5), 2745-2763.

Malik, K. M., Mahmood, A., Kazmi, D. H., \& Khan, J. M. (2012). Impact of climate change on agriculture during winter season over Pakistan. Agricultural Sciences,3(8),10071018.,http://search.proquest.com/docview/1272087473?accountid= 10920, retrieved on $14^{\text {th }}$ February 2014.

Manatsa, D. Matarira, C. \& Mukwad, G (2011). Relative impacts of ENSO and Indian Ocean dipole/zonal mode on east SADC rainfall. International Journal of Climatology, 31, $558-577$.

Marchant, R., Mumbi, C., Behera, S. \& Yamagata, T. (2007). The Indian Ocean dipole - the unsung driver of climatic variability in East Africa. African Journal of Ecology, 45, 416.

Mary, A. L. \& Majule, A. E. (2009). Impacts of climate change, variability and adaptation strategies on agriculture in semi-arid areas of Tanzania, The case of Manyoni District in Singida Region, Tanzania. Environmental Science and Technology, 3 (8), 206 - 218. 
McGrath, M. (2020). Climate change: Last decade confirmed as warmest on record. $B B C$ News, 15.

Mongi, H., Majule, A. \& Lyimo, J. (2010). Vulnerability and adaptation of rain - fed agriculture to climate change and variability in semi - arid Tanzania. African Journal of Environmental Science and Technology, 4 (6), 371 - 381.

Nicholson, S. E., D. Leposo, \& J. Grist. (2001). The relationship between El Nino and drought over Botswana. Journal of Climate, 14 (3), 323-335.

Owusu, K. (2009). Changing rainfall climatology of West Africa: Implications for rainfed agriculture in Ghana and water sharing in the Volta basin. Unpubulished Doctorial dissertation, University of Florida, USA.

Owusu-Sekyere, J. D., Andoh, J., \& Nyarko, K. (2011). Climate Change and Crop Production in the Mfantseman Area of Ghana. Journal of Applied Environmental and Biological Sciences, 1(7), 134-141.

Park, S., Kang, D., Yoo, C., Im, J., \& Lee, M. I. (2020). Recent ENSO influence on East African drought during rainy seasons through the synergistic use of satellite and reanalysis data. ISPRS Journal of Photogrammetry and Remote Sensing, 162, 17-26.

Recha, C.W., Shisanya, C.A., Anyamba, A., \& Okolla, J. (2013), Determinants of seasonal rainfall and forecast skills in semi-arid south- east Kenya, Journal of the Geographical Association of Tanzania, 34, $1-14$.

Salinger, J., Sivakumar, M. \& Motha, R (2005). Increasing climate variability and change: Reducing the variability of agriculture and forestry, Springer, Netherlands.

Sarr, B. (2012). Present and future climate change in the semi-arid region of West Africa: A crucial input for practical adaptation in agriculture. Atmospheric Science Letters from wileyonlinelibrary.com accessed on 27 December 2019.

Sivakumar, M. V. K., Das, H. P., \& Brunini, O. (2005). Impacts of present and future climate variability and change on agriculture and forestry in the arid and semi-arid tropics. Climatic Change, 70 (1\&2) 31-72.

Swai, O. W., Mbwambo, J. S., \& Magayane, F. T. (2012). Gender and adaption practices to the effects of climate change in Bahi and Kondoa districts Dodoma region, Tanzania. Journal of Sustainable Development, 5 (12), 65-77.

Umar, A. T., \& Bako, M. M. (2019). Recent Rainfall Trends and Variability in SudanoSahelian Region of Nigeria (1986-2015). Ghana Journal of Geography, 11(1), 33-57.

United Republic of Tanzania, URT (2007). National sample census of agriculture 2002/2003; Regional report: Dodoma Region, Volume V-A. Government Printer, Dar es Salaam.

United Republic of Tanzania, URT (2011). Basic data: Agriculture and cooperative sector 2005/2006 - 2009/2010; statistics unit, planning and marketing division, Government Printer, Dar es Salaam.

World Meteorological Organization. (2014, January 24). Climate Data Online. http://www.ncdc.noaa.gov/cdo-web/

World Wide Fund for Nature, WWF (2006). Climate change impacts on east Africa: A review of the scientific literature.

Yang, W., Seager, R., Cane, M. A., \& Lyon, B. (2015). The annual cycle of the East African precipitation. Journal of Climatology, 28 (6), 2385-2404. 